\title{
Helping people in a minimally conscious state develop responding and stimulation control through a microswitch-aided program
}

\author{
Giulio E. LANCIONI ${ }^{1 *}$, Nirbhay N. SINGH ${ }^{2}$, Mark F. O’REILLY ${ }^{3}$, Jeff SIGAFOOS ${ }^{4}$, \\ Fiora D’AMICO ${ }^{5,6}$, Francesca BUONOCUNTO ${ }^{7}$, Jorge NAVARRO ${ }^{7}$, Crocifissa LANZILOTTI 7 , \\ Pietro FIORE ${ }^{8}$, Marisa MEGNA ${ }^{8}$, Sabino DAMIANI ${ }^{8}$, Riccardo MARVULLI 8
}

\begin{abstract}
${ }^{1}$ Department of Neuroscience and Sense Organs, University of Bari, Bari, Italy; ${ }^{2}$ Medical College of Georgia, Augusta University, Augusta, GA, USA; ${ }^{2}$ Department of Special Education, University of Texas, Austin, TX, USA; ${ }^{4}$ School of Education, Victoria University of Wellington, Wellington, New Zealand; ${ }^{5}$ Lega F. D’Oro Research Center, Osimo, Ancona, Italy; 6 S. Raffaele Care Center, Alberobello, Bari, Italy; ${ }^{7}$. Raffaele Rehabilitation Center, Ceglie, Brindisi, Italy; ${ }^{8}$ Department of Physical and Rehabilitation Medicine, Polyclinic of Bari, Bari, Italy
\end{abstract}

*Corresponding author: Giulio E. Lancioni, Department of Neuroscience and Sense Organs, University of Bari, Corso Italia 23, 70121 Bari, Italy. E-mail: giulio.lancioni@uniba.it

\section{A B S T R A C T}

BACKGROUND: Postcoma persons in a minimally conscious state (MCS) and with extensive motor impairment cannot independently access and control environmental stimulation.

AIM: Assessing the effects of a microswitch-aided program aimed at helping MCS persons develop responding and stimulation control and conducting a social validation/evaluation of the program.

DESIGN: A single-subject ABAB design was used for each participant to determine the impact of the program on his or her responding. Staff interviews were used for the social validation/evaluation of the program.

SETTING: Rehabilitation and care facilities that the participants attended.

POPULATION: Eleven MCS persons with extensive motor impairment and lack of speech or any other functional communication.

METHODS: For each participant, baseline (A) phases were alternated with intervention (B) phases during which the program was used. The program relied on microswitches to monitor participants' specific responses (e.g., prolonged eyelid closures) and on a computer system to enable those responses to control stimulation. In practice, the participants could use a simple response such as prolonged eyelid closure to generate a new stimulation input. Sixty-six staff people took part in the social validation of the program. They were to compare the program to basic and elaborate forms of externally controlled stimulation, scoring each of them on a six-item questionnaire.

RESULTS: All participants showed increased response frequencies (and thus higher levels of independent stimulation input/control) during the $\mathrm{B}$ phases of the study. Their frequencies for each intervention phase more than doubled their frequencies for the preceding baseline phase with the difference between the two being clearly significant $(\mathrm{P}<0.01)$. Staff involved in the social validation procedure provided significantly higher scoring $(\mathrm{P}<0.01)$ for the program on five of the six questionnaire items.

CONCLUSIONS: A microswitch-aided program can be an effective and socially acceptable tool in the work with MCS persons.

CLINICAL REHABILITATION IMPACT: The participants and staff's data can be taken as an encouragement for the use of a microswitch-aided program within care and rehabilitation settings for MCS persons.

(Cite this article as: Lancioni GE, Singh NN, O'Reilly MF, Sigafoos J, D'Amico F, Buonocunto F, et al. Helping people in a minimally conscious state develop responding and stimulation control through a microswitch-aided program. Eur J Phys Rehabil Med 2017;53:433-40. DOI: 10.23736/ S1973-9087.16.04324-0)

Key words: Self-help devices - Persistent vegetative state - Program evaluation.

$\mathrm{P}$ ostcoma people in a minimally conscious state (MCS) often present with extensive motor impairment, lack of speech, and general passivity and isola- tion. ${ }^{1-5}$ An immediate concern about their situation is the reduced level of environmental stimulation that they can access and experience. ${ }^{6-8}$ This concern and the re- 


\section{COPYRIGHT $^{(} 2017$ EDIZIONI MINERVA MEDICA}

LANCIONI

RESPONDING AND STIMULATION CONTROL

alization that an enriched environment may be essential for promoting their recovery process (e.g., neural reactivation and awareness) have prompted the development of various intervention approaches. ${ }^{6-11}$

The most frequently used approach involves periods of environmental stimulation controlled by the caregiver/therapist. ${ }^{2}$ In its basic form, this approach consists of the presentation of simple, daily stimulus events such as music and verbal inputs. ${ }^{2,5,6,12-14}$ In its more elaborate forms, this approach involves the presentation of intensive multisensory stimulation, a physically and verbally guided manipulation of relevant daily objects or the exposure to emotional and autobiographical stories. ${ }^{7,10,15-17}$

A second approach involves the use of: 1) transcranial magnetic stimulation (i.e., magnetic fields to stimulate nerve cells in the brain);18, 19 2) deep brain stimulation (i.e., electrical stimulation of the thalamus through implanted electrodes). ${ }^{19-22}$ The former stimulation is easy to apply and totally safe while the latter stimulation is still at the experimental stage and poses questions about its general applicability and safety. 19,20

A third approach involves the use of microswitchaided programs to empower participants to control environmental stimulation through their responses.23-25 In practice, the participants are allowed to use small, basic responses to: 1) activate specific microswitches (i.e., sensors); or 2) trigger, through the microswitches, a computer system; and 3) cause this system to present brief periods of preferred environmental stimulation (i.e., thus regulating their stimulation inputs). ${ }^{2,25}$

A microswitch-aided program could be considered a critical component of any intervention protocol for MCS persons, given its distinctive emphasis on the people's active role (i.e., self-regulation of response and stimulation events) and apparent effectiveness in promoting such a role, with presumably positive implications for the people's recovery process. ${ }^{2}$ While a few studies have reported encouraging results using a microswitchaided program, research extension (i.e., systematic replication efforts) 26,27 with the inclusion of additional participants and new or adapted responses and microswitches seems needed before this type of program can be recommended for use within care and rehabilitation centers. Further support for this type of program would be obtained from a social validation assessment if this indicated that staff personnel prefer the program to the use of externally controlled stimulation. ${ }^{25}$ The present study pursued the aforementioned research lines by assessing a microswitch-aided program with 11 new MCS participants, and carrying out a social validation assessment in which staff personnel working in the multiple disabilities area were interviewed about the program and about stimulation conditions such as those of the first approach (see above). 27,28

\section{Materials and methods}

\section{Participants}

A total of 15 MCS people were selected for this study. Eleven of them completed the study and are here reported as the participants, two were withdrawn due to health complications, and two died. The participants were in rehabilitation and care centers and their condition followed brain injury and coma. They represented a convenience sample ${ }^{29}$ characterized by: 1) presence of extensive motor impairment and lack of speech or any other functional communication; 2) reliance on a gastrostomy or nasogastric tube for enteral nutrition; and 3) use of a tracheostomy tube (i.e., except for participants 8 and 11). Table I reports the participants' sex, age and coma durations, and the intervals between the occurrence of their brain injury and the start of the study. Their brain injury was connected to a variety of conditions involving: right tentorial meningioma resection (participant 1 ), extended posterior circulation ischemic stroke (participant 2), left total anterior circulation stroke with extended left fronto-temporo-parietal ischemic lesion (participants 3 and 10), aneurism rupture of left middle cerebral artery with subsequent extended subarachnoid and intraventricular hemorrhage (participant 4), exten-

\begin{tabular}{lcccc}
$\begin{array}{l}\text { TABLE I. Participants'sex, age and coma durations, and intervals } \\
\text { between }\end{array}$ \\
\hline brain injury and start of the study. \\
\hline Participants & Sex & $\begin{array}{c}\text { Ages } \\
\text { (years) }\end{array}$ & $\begin{array}{c}\text { Coma durations } \\
\text { (weeks) }\end{array}$ & $\begin{array}{c}\text { Intervals between brain } \\
\text { injury and study (months) }\end{array}$ \\
\hline 1 & F & 67 & 2 & 2.5 \\
2 & F & 71 & 2 & 2.5 \\
3 & M & 80 & 1 & 2 \\
4 & F & 81 & 1 & 2 \\
5 & F & 72 & 2 & 48 \\
6 & F & 56 & 3 & 3 \\
7 & F & 77 & 2 & 4 \\
8 & M & 38 & 2 & 12 \\
9 & F & 76 & 3 & 4 \\
10 & F & 75 & 2 & 2 \\
11 & F & 49 & 1 &
\end{tabular}




\section{COPYRIGHT $^{(} 2017$ EDIZIONI MINERVA MEDICA}

RESPONDING AND STIMULATION CONTROL

LANCIONI

sive left or right frontotemporo-parietal intraparenchymal hemorrhage (participants 5 and 9), severe hypoxic ischemic encephalopathy (participant 6), left temporoparietal intraparenchymal hemorrhage (participant 7), diffuse herpes simplex encephalitis (participant 8), and repeated bilateral fronto-parietal ischemic strokes (participant 11).

Their subscale and total scores on the Coma Recovery Scale-Revised (CRS-R) ${ }^{30}$ are shown in Table II. The total scores ranged from 7 to 16 . The subscale scores allowing a diagnosis of MCS are indicated with an asterisk. Differences in etiology/history and CRS-R scores were not seen as a methodological problem because the effects of the microswitch-aided program were evaluated on an individual basis via a within-subject experimental design (see the paragraph "Experimental design and conditions"). The participants' involvement in the study was considered to be valuable by their families and care and rehabilitation staff. In fact, such an involvement allowed them to practice response engagement with possible increases in alertness and attention, and learn to control stimulation (all of which were deemed crucial for the recovery process). 23,25 The participants' families had signed a formal consent for their involvement in this study, which complied with the 1964 Helsinki declaration and its later amendments and was approved by institutional Ethics Committees.

\section{Setting, responses, technology, and stimuli}

Sessions were carried out in the participants' room, within the rehabilitation and care facilities that they

TABLE II.-Participants'scores on the CRS-R.

\begin{tabular}{|c|c|c|c|c|c|c|c|}
\hline \multirow[b]{2}{*}{ Participants } & \multicolumn{6}{|c|}{ Subscales' Scores } & \multirow[b]{2}{*}{$\begin{array}{l}\text { Total } \\
\text { score }\end{array}$} \\
\hline & Arousal & $\begin{array}{l}\text { Oral/ } \\
\text { motor }\end{array}$ & Motor & $\begin{array}{l}\text { Com- } \\
\text { munica- } \\
\text { tion }\end{array}$ & Visual & $\begin{array}{c}\text { Audi- } \\
\text { tory }\end{array}$ & \\
\hline 1 & 2 & 2 & $5 *$ & $1 *$ & $3 *$ & $3 *$ & 16 \\
\hline 2 & 2 & 0 & 2 & 0 & $2 *$ & 2 & 8 \\
\hline 3 & 2 & 0 & 1 & 0 & $3 *$ & 2 & 8 \\
\hline 4 & 2 & 0 & $5 *$ & 0 & $3 *$ & $3 *$ & 13 \\
\hline 5 & 2 & 0 & 2 & $1 *$ & 1 & 1 & 7 \\
\hline 6 & 2 & 1 & 2 & 0 & 1 & $3 *$ & 9 \\
\hline 7 & 2 & 1 & $5 *$ & $1 *$ & $3 *$ & $3 *$ & 15 \\
\hline 8 & 2 & 1 & $5 *$ & 0 & $3 *$ & 2 & 13 \\
\hline 9 & 2 & 1 & 2 & 0 & $2 *$ & 2 & 9 \\
\hline 10 & 2 & 1 & 2 & 0 & $3 *$ & 2 & 10 \\
\hline 11 & 2 & 1 & 1 & 0 & $3 *$ & $3 *$ & 10 \\
\hline
\end{tabular}

*MCS attended. The participants were in a reclined position, in bed or in a special wheelchair. The responses were selected on the basis of their suitability for the participants and consisted of eyelid or hand closure, eyebrow upward movement, lateral head movement, and lips/ mouth movement. Table III lists the responses and microswitches used by the 11 participants. Eyelid closure involved a protracted blink/closure (i.e., longer than 0.6 seconds) or a repeated blink (i.e., two eyelid closures within a 2 -second interval). ${ }^{31}$ Hand closure consisted of moving the fingers of the right or left hand toward the palm of the same hand). ${ }^{31}$ Eyebrow upward movement consisted of raising the right eyebrow for more than 2 mm. ${ }^{31}$ Lateral head movement consisted of reclining or turning the head to the right side. ${ }^{31} \mathrm{Lips} /$ mouth movement consisted of opening and/or closing the lips. ${ }^{31}$ The eyelid responses were detected via an optic microswitch (i.e., an infrared light-emitting diode and a mini infrared light-detection unit of about $1 \mathrm{~cm} \times 0.6$ $\mathrm{cm} \times 0.5 \mathrm{~cm}$ ), which was kept with medical tape on the participants' left or right cheekbone and used together with a mini paper sticker attached to the corresponding eyelid. ${ }^{31}$ The hand closure responses were detected via a touch or a pressure microswitch fixed into the palm of the participants' hand. ${ }^{31}$ Eyebrow, head, and lips/mouth movements were detected via optic microswitches, such as the one used for eyelid responses, placed on the participant's forehead, right collarbone, and corner of the mouth, respectively. Microswitch activation (i.e., response detection) triggered a computer system that counted the response occurrences (during all phases of the study) and ensured stimulation contingent on

\begin{tabular}{lll} 
TABLE III__- Participants'responses and microswitches. \\
\hline Participants & Responses & Microswitches \\
\hline 1 & Protracted eyelid closure & Optic microswitch \\
2 & Protracted eyelid closure & Optic microswitch \\
3 & Repeated eyelid closure & Optic microswitch \\
4 & Hand closure & Touch microswitch \\
5 & Protracted eyelid closure & Optic microswitch \\
6 & Eyebrow upward movement & Optic microswitch \\
7 & Hand closure & Pressure microswitch \\
8 & Lateral head movement & Optic microswitch \\
9 & Lips/mouth movement & Optic microswitch \\
10 & Protracted eyelid closure & Optic microswitch \\
11 & Repeated eyelid closure & Optic microswitch \\
\hline
\end{tabular}




\section{COPYRIGHT $^{(} 2017$ EDIZIONI MINERVA MEDICA}

each occurrence (during the intervention phases of the study).

The stimuli scheduled to follow the participants' responding during the intervention phases of the study included video clips of events, such as singing, praying, or eating and dancing, and audio-recordings of songs, comedy, and voices of loved ones speaking to them. Those stimuli had been recommended by the participants' families as being in line with the participants' preinjury preferences and were also deemed practical to use. ${ }^{4}$

\section{Experimental design and conditions}

A single-subject $\mathrm{ABAB}$ design (with $\mathrm{A}$ and $\mathrm{B}$ representing baseline and intervention with the microswitchaided program for stimulation control) was used for each participant to assess the impact of the program..$^{32}$ Baseline and intervention sessions lasted 5 minutes. Three to 11 sessions per day were carried out depending on the participants' availability and wakefulness (i.e., a condition needed for implementing the sessions). After the end of the second intervention phase, a social validation assessment took place (see below).

The participants' responses during baseline and intervention sessions were automatically recorded by the computer system. Response prompting (e.g., a light air puff to the corner of the participant's eye or a touch on the participant's hand) to bring about the target response was used prior to the sessions as well as during the sessions if the participant failed to respond for 30-45 seconds. Research assistants familiar with microswitchaided programs delivered the prompting and also subtracted any response occurred after prompting from the computer tally, at the end of the sessions. Agreement between assistants on recording these responses (whose occurrence frequency could also be zero) was assessed in 30 sessions. In each of those sessions, the assistants' scores corresponded, thus indicating complete agreement.

\section{BASELINE (A) I AND II}

The baseline phases included between 4 and 11 sessions and ended only if the response frequency of the last session did not exceed that of the previous sessions. During the baseline sessions, the microswitch and com- puter were used for recording the responses, but no stimulation was available.

\section{INTERVENTION (B) I AND II}

The two intervention phases included 45-71 and 66143 sessions, respectively (with differences in numbers largely due to participants' availability). Conditions varied from the baseline in that each response was followed by a 10 -second stimulation period. Intervention I was preceded by six to eight practice sessions in which research assistants' prompting was extensively used to foster the participants' experience of their target response and related stimulation.

\section{Social validation assessment}

Completed the intervention, each participant was involved in six to eight 5-minute control sessions that were to be used for the social validation assessment (see below). Three or four of those sessions entailed basic forms of environmental stimulation (e.g., music and videos similar to those used in the intervention phases), which occurred uninterruptedly. The other three or four sessions entailed elaborate forms of environmental stimulation with a research assistant guiding the participant through the manipulation of a relevant daily object (e.g., a music instrument or a kitchen utensil) and talking/reminiscing about its use. ${ }^{16}$ These two types of sessions mirrored stimulation strategies of the first approach described in the Introduction.

Sixty-six staff persons working in care and/or rehabilitation centers for people with multiple disabilities with or without consciousness disorders (i.e., nurses, physiotherapists, physicians, and occupation/education therapists) participated in the social validation assessment. They were between 25 and $71(\mathrm{M}=36)$ years of age, represented a convenience sample, ${ }^{29}$ and were divided into 11 groups of six. Each group was asked to watch a 7-minute video of one of the 11 participants who completed the study. The video contained three segments of slightly more than 2 minutes, that is one segment of the participant during a standard intervention session with the microswitch-aided program, one segment of the participant during a control session with basic environmental stimulation, and one segment of the participant during a control session with elaborate 


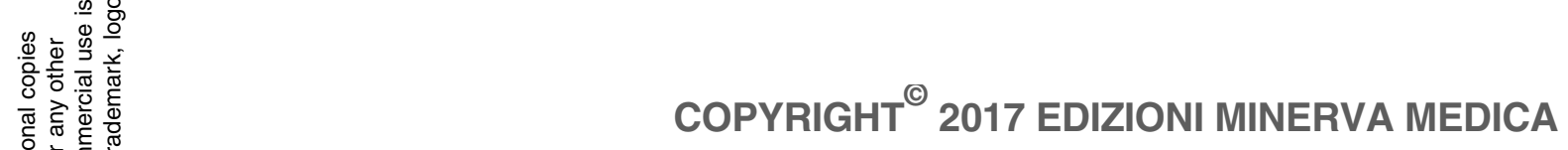

RESPONDING AND STIMULATION CONTROL

LANCIONI

TABLE IV.-Questionnaire items.

1. Do you think that this condition promotes the participant's self-determination (initiative) in accessing/controlling stimulation?

2. Do you think that this condition can help the participant in the recovery process by increasing some purposeful activation?

3. Do you think that this condition helps the participant display a more positive (less passive) image of him- or herself?

4. Do you think that caregivers and family members find this condition useful for the participant?

5. Do you think that this condition is easily applicable in care and home settings?

6. Would you like to be involved in the implementation of this condition?

environmental stimulation. The order of the segments varied across participants. Those segments had been selected by research assistants on the agreement that they were illustrative of the participants' behavior within the three conditions. After watching the video, staff scored each of the segments/conditions on a 6-item questionnaire (Table IV). Item scores could vary from 1 (i.e., least positive value) to 5 (i.e., most positive value).

\section{Data analysis}

In line with single-subject research literature, the data for the $11 \mathrm{MCS}$ participants during the $\mathrm{ABAB}$ design sequence were displayed on graphs for an immediate visual inspection of differences in overall frequencies and trends. ${ }^{27}, 32$ A nonparametric test (KolmogorovSmirnov) was then used for each participant to determine whether the differences in response frequencies during the baseline and the intervention phases were statistically significant. ${ }^{33}$ The procedure followed for the social validation assessment led every staff person to score the three conditions observed in the video on each item of the questionnaire. This resulted in three sets of 66 scores (one set per condition) per item. Data analysis consisted of comparing the scores of the intervention condition with the scores of each of the two control conditions for every item of the questionnaire separately. Paired $t$ tests were used to determine whether the score differences between conditions were statistically significant. ${ }^{34}$

\section{Results}

The four panels of Figures 1 and 2 summarize the data for participants 1 to 4 and participants 5 to 8 , re-

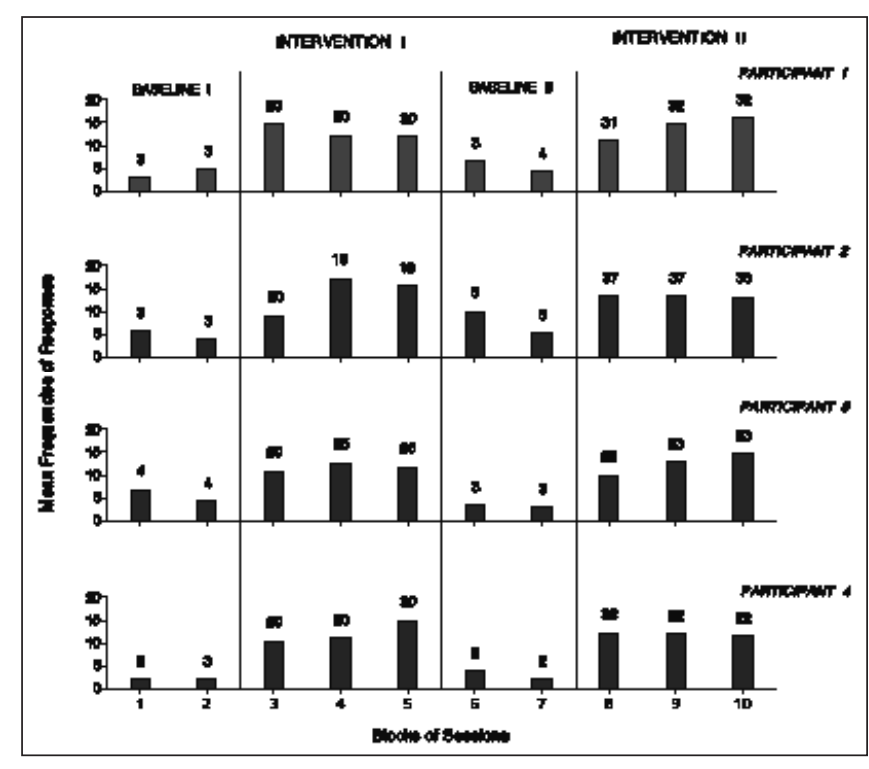

Figure 1.-The four panels summarize the data for participants 1 to 4 , respectively. The bars indicate mean frequencies of responses per session over blocks of baseline and intervention sessions. The number of sessions included in each block is indicated by the numeral above it.

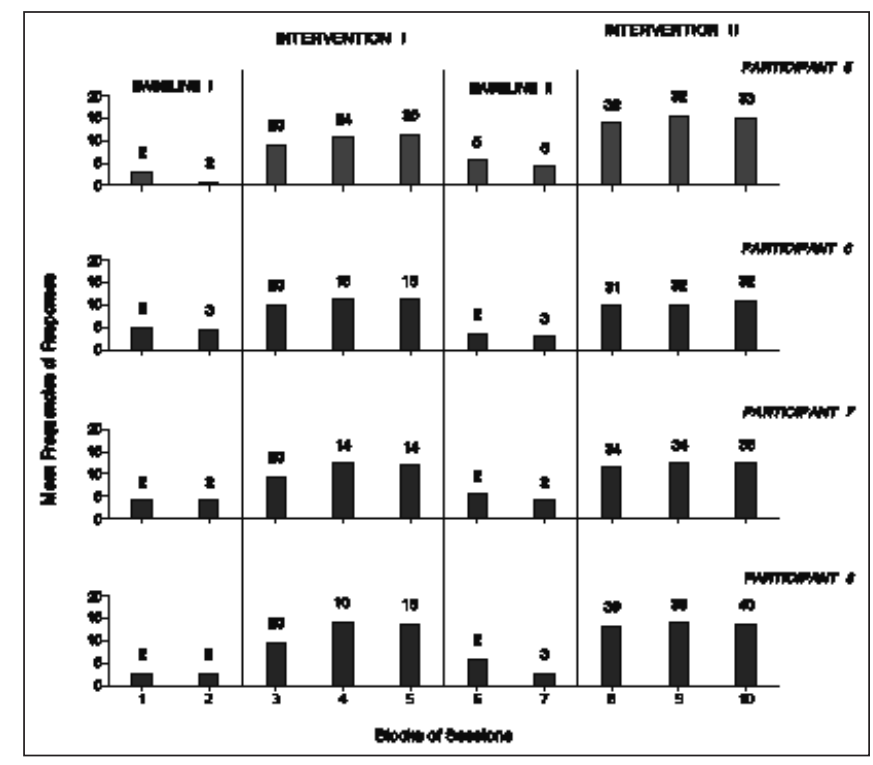

Figure 2.-The four panels summarize the data for participants 5 to 8 , respectively. Data are plotted as in Figure 1.

spectively. The three panels of Figure 3 summarize the data for participants 9 to 11 . The bars indicate mean frequencies of responses per session over blocks of 


\section{COPYRIGHT ${ }^{\odot} 2017$ EDIZIONI MINERVA MEDICA}

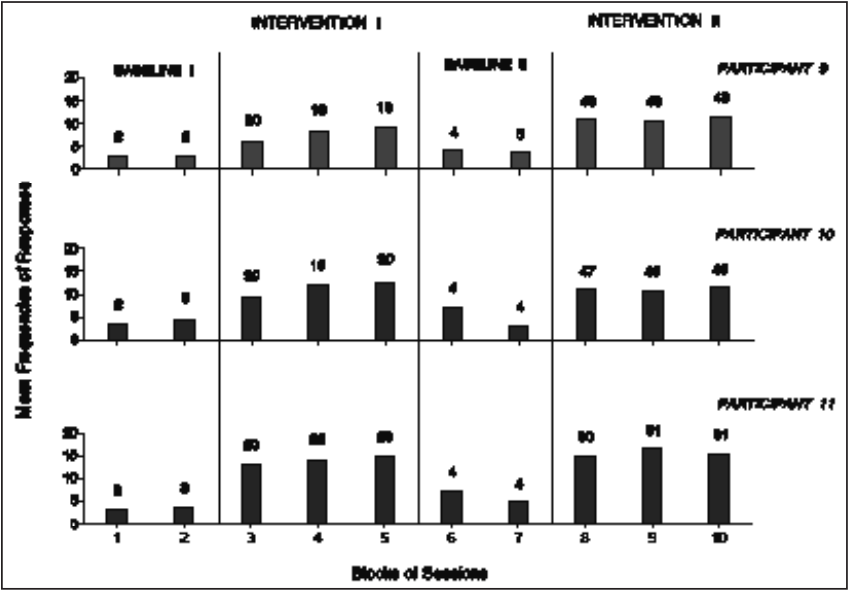

Figure 3.-The three panels summarize the data for participants 9 to 11 , respectively. Data are plotted as in Figure 1.

baseline and intervention sessions. The number of sessions included in each block is indicated by the numeral above it. To provide a clear picture of early response increases, the number of sessions included in the initial block of the first intervention phase is identical (i.e., 20) across participants, irrespective of their total number of sessions for that phase. During the first baseline phase, the participants' mean frequencies of responses were between two (participants 4 and 5) and slightly over five (participant 3). During the first intervention phase, those means increased to between above eight (participant 9) and 14 (participants 2 and 11). During the second baseline, all participants showed a response decline. During the second intervention phase, their mean frequencies increased again. In practice, the participants' response frequencies for each intervention phase more than doubled their frequencies for the preceding baseline phase. The Kolmogorov-Smirnov Test confirmed that the response differences between each intervention phase and the preceding baseline were statistically significant $(\mathrm{P}<0.01)$ for every participant. ${ }^{33}$ No definite links seemed to exist between type of response/microswitch or CRS-R scores and intervention response frequencies. For example, participants 2 and 10 , who used the same response and microswitch and had similar CRS-R scores, showed relatively high and relatively low response frequencies, respectively.

The staff's mean scores and standard deviations for the single questionnaire items across the intervention and the two control conditions are summarized in Table
TABLE V.-Staff's mean scores $(M)$ and standard deviations (SD) for the questionnaire items over the intervention and the control (basic and elaborate) conditions.

\begin{tabular}{|c|c|c|c|c|c|c|}
\hline \multirow{3}{*}{ Items } & \multicolumn{6}{|c|}{ Conditions } \\
\hline & \multicolumn{2}{|c|}{ Intervention } & \multicolumn{2}{|c|}{ Control (basic) } & \multicolumn{2}{|c|}{ Control (elaborate } \\
\hline & M & SD & M & SD & M & SD \\
\hline 1 & 4.29 & 0.65 & 2.36 & 1.15 & 2.73 & 0.89 \\
\hline 2 & 3.95 & 0.75 & 2.52 & 0.95 & 2.76 & 0.80 \\
\hline 3 & 4.02 & 0.81 & 2.45 & 1.03 & 2.97 & 0.89 \\
\hline 4 & 3.95 & 0.73 & 2.80 & 0.93 & 3.18 & 0.84 \\
\hline 5 & 3.59 & 0.88 & 3.39 & 1.02 & 3.53 & 0.75 \\
\hline 6 & 3.73 & 0.90 & 2.61 & 1.08 & 3.02 & 0.97 \\
\hline
\end{tabular}

V. The mean scores per item varied between: 1) 2.36 and 3.39 in relation to the control condition with basic environmental stimulation; 2) 2.73 and 3.53 in relation to the control condition with elaborate environmental stimulation; and 3) 3.59 and 4.29 in relation to the intervention condition (i.e., with the microswitch-aided program and stimulation contingent on responses). Paired $t$-tests indicated that the differences between the intervention condition and each of the two control conditions were statistically significant $(\mathrm{P}<0.01)$ on all items except the fifth (i.e., the one concerning the applicability of the condition in care and home settings), with $t$ values ranging from 5.84 to $12.30 .{ }^{34}$

\section{Discussion}

The results are highly encouraging with regard to each of the two issues investigated in the study. That is, the microswitch-aided program was effective in helping the participants develop responding and stimulation control in line with the data of previous studies. $2,24,25$ Staff working with people with multiple disabilities scored the program better than the control conditions in five of the questionnaire items (including those on participants' initiative, recovery process, and general image), thus extending preliminary findings in this area. ${ }^{25}$ In light of the above, a number of considerations may be put forward.

First, a microswitch-aided program differs from externally controlled stimulation approaches (see Introduction) in that it aims to enable the participants to develop functional responding and manage environmental stimulation directly. Functional responding and stimulation control suggest increased participants' attentiveness and self-determination and possibly entail higher 


\section{COPYRIGHT $^{(} 2017$ EDIZIONI MINERVA MEDICA}

RESPONDING AND STIMULATION CONTROL

LANCIONI

levels of enjoyment than simple exposure to stimulation. ${ }^{23,35-37}$ Increases in attentiveness and self-determination can be considered valuable achievements, instrumental to foster the recovery process of participants like those included in this study.11, 24, 38 High levels of stimulation enjoyment would be relevant to improve the participants' life condition and motivate them to maintain their active engagement. ${ }^{39-41}$

Second, the positive results described above extend the encouraging evidence on the effectiveness of microswitch-aided intervention. ${ }^{2}, 25,27$ This extension/ confirmation underlines the reliability of the approach and its promise for MCS persons. ${ }^{26,27}$ Although very important, this confirmation could hardly be considered sufficient by itself to guarantee the adoption of a microswitch-aided program within rehabilitation and care centers. ${ }^{25}$ In fact, such an adoption might be based not simply on the overall impact of the program, but also on the way the program is perceived. ${ }^{42}$ In light of this, the social validation assessment carried out in the present study was viewed as a necessary component of the study, and the positive evidence emerging from the staff interviews was taken as an indication of the acceptability of the program. 25,28

Third, while the aforementioned dependability and social acceptability variables might be critical for the adoption of a microswitch-aided program in daily contexts, the technology required for its implementation may have a role in determining its long-term use within such contexts. ${ }^{2}, 43,44$ With regard to this point, the first consideration is that the technology employed in the present study is fairly affordable. In fact, it may generally be set up through the use of relatively inexpensive microswitches and interfaces, and a portable computer with basic software. ${ }^{25,45}$ A second consideration is that microswitch-aided sessions may be easily integrated within a protocol that includes other treatments such as transcranial magnetic stimulation or elaborate forms of environmental stimulation. ${ }^{25}$

\section{Limitations of the study}

A main limitation of this study is the lack of specific measures of the level of participants' alertness/attentiveness during the intervention sessions with the program and possible differences between such level and that attainable during exposure to externally controlled stimulation. ${ }^{23}, 35$ The presumed advantages of the intervention sessions with regard to alertness/attentiveness should be verified by new research using behavioral criteria (e.g., eye opening and eye movements) as well as electrophysiological data such as heart rate variability, respiration patterns and skin conductance. ${ }^{46} \mathrm{New}$ research should also assess additional microswitches, such as camera-based and Kinect-like microswitches, and determine their advantages and drawbacks in relation to the microswitches currently used. ${ }^{25,47}$

\section{Conclusions}

In conclusion, the results of this study provide new evidence on the effectiveness of a microswitch-aided program and the staff's endorsement of it. 32 New research should identify ways of measuring participants' alertness/attentiveness during the use of such a program and during free stimulation sessions, extend the assessment of the program and the support for it with additional participants and across different research groups and care and rehabilitation centers, and develop and evaluate new, easy-to-use microswitches for small responses, so as to extend the range of tools available for participants with pervasive motor impairment. ${ }^{26,27,45,48}$

\section{References}

1. Bruno MA, Vanhaudenhuyse A, Thibaut A, Moonen G, Laureys S. From unresponsive wakefulness to minimally conscious PLUS and functional looked-in syndromes: Recent advances in our understanding of disorders of consciousness. J Neurol 2011;258:1373-84.

2. Lancioni GE, Bosco A, Olivetti Belardinelli M, Singh NN, O'Reilly $\mathrm{MF}$, Sigafoos J, et al. Technology-based intervention programs to promote stimulation control and communication in post-coma persons with different levels of disability. Front Hum Neurosci 2014;8:48.

3. Lancioni GE, Olivetti Belardinelli M, Oliva D, Signorino M, De Tommaso M, Megna G, et al. Successful extension of assessment and rehabilitation intervention for an adolescent with postcoma multiple disabilities through a learning setup. Eur J Phys Med Rehabil 2008;44:449-53

4. Whyte J. Treatments to enhance recovery from the vegetative and minimally conscious states. Am J Phys Med Rehabil 2007;86:86-92.

5. Daveson B. An audit about music therapy assessments and recommendations for adult patients suspected to be in a low awareness state. J Music Ther 2010;47:408-22.

6. Hirschberg R, Giacino JT. The vegetative and minimally conscious states: Diagnosis, prognosis and treatment. Neurol Clin 2011;29:77386.

7. Abbate C, Trimarchi PD, Basile I, Mazzucchi A, Devalle G. Sensory stimulation for patients with disorders of consciousness: From stimulation to rehabilitation. Front Hum Neurosci 2014;8:616.

8. McNamee S, Howe L, Nakase-Richardson R, Peterson M. Treatment of disorders of consciousness in the Veterans Health Administration polytrauma centers. J Head Trauma Rehab 2012;27:244-52. 


\section{COPYRIGHT $^{(} 2017$ EDIZIONI MINERVA MEDICA}

LANCIONI

RESPONDING AND STIMULATION CONTROL

9. Müller-Patz GR, Pokorny C, Klobassa DS, Horki P. A single-switch $\mathrm{BCI}$ based on passive and imagined movements: Toward restoring communication in minimally conscious patients. Int J Neural Syst 2013;23:1250037.

10. Pape TLB, Rosenow J, Steiner M, Parrish T, Guernon A, Harton B, et al. Placebo-controlled trial of familiar auditory sensory training for acute severe traumatic brain injury: A preliminary report. Neurorehab Neural Re 2015;29:537-47.

11. Seel RT, Douglas J, Dennison AC, Hearner S, Farris K, Rogers C. Specialized early treatment for persons with disorders of consciousness: Program components and outcomes. Arch Phys Med Rehab 2013;94:1908-23.

12. Georgiopoulos M, Katsakiori P, Kefalopoulou Z, Ellul J, Chroni E, Constantoyannis C. Vegetative state and minimally conscious state: A review of the therapeutic interventions. Stereot Funct Neuros 2010;88:199-207.

13. Giacino JT. Sensory stimulation: Theoretical perspectives and the evidence for effectiveness. NeuroRehabilitation 1996;6:69-78.

14. Magee WL. Music as a diagnostic tool in low awareness states: Considering limbic responses. Brain Inj 2007;21:593-9.

15. Lotze M, Schertel K, Birbaumer N, Kotchoubey B. A long-term intensive behavioral treatment study in patients with persistent vegetative state or minimally conscious state. J Rehab Med 2011;43:230-6.

16. Di Stefano C, Cortesi A, Masotti S, Simoncini L, Piperno R. Increased behavioural responsiveness with complex stimulation in VS and MCS: Preliminary results. Brain Inj 2012;26:1250-6.

17. Pape TLB, Rosenow JM, Harton BS, Patil V, Guernon A, Parrish T, et al. Preliminary framework for Familiar Auditory Sensory Training (FAST) provided during coma recovery. J Rehabil Res Dev 2012;49:1137-52.

18. Angelakis E, Liouta E, Andreadis N, Korfias P, Stranialis G, Sakas DE. Transcranial direct current stimulation (tDCS) effects in disorders of consciousness. Arch Phys Med Rehab 2014;95:283-9.

19. Shin SS, Dixon CE, Okonkwo DO, Richardson RM. Neurostimulation for traumatic brain injury. J Neurosurg 2014;121:1219-31.

20. Giacino J, Fins JJ, Machado A, Schiff ND. Central thalamic deep brain stimulation to promote recovery from chronic posttraumatic minimally conscious state: Challenges and opportunities. Neuromodulation 2012;15:339-49.

21. Schiff ND, Giacino JT, Fins JJ. Deep brain stimulation, neuroethics, and the minimally conscious state. Arch Neurol 2009;66:697-702.

22. Yamamoto T, Katayama Y, Obuchi T, Kobayashi K, Oshima H, Fukaya C. Deep brain stimulation and spinal cord stimulation for vegetative state and minimally conscious state. World Neurosurg 2013;80:S30.e1-S30.e9.

23. Lancioni GE, Singh NN, O'Reilly MF, Green VA, Buonocunto F, Sacco V, et al. Microswitch-aided programs with contingent stimulation versus general stimulation programs for post-coma persons with multiple disabilities. Dev Neurorehabil 2014;17:251-8.

24. Lancioni GE, Singh NN, O'Reilly MF, Sigafoos J, Amenduni MT, Navarro J, et al. Microswitch technology and contingent stimulation to promote adaptive engagement in persons with minimally conscious state: A case evaluation. Cogn Process 2012;13:133-7.

25. Lancioni GE, Singh NN, O'Reilly MF, Sigafoos J, D'Amico F, Buonocunto $\mathrm{F}$, et al. Assistive technology to help persons in a minimally conscious state develop responding and stimulation control: Performance assessment and social rating. NeuroRehabilitation 2015;37:393-403.

26. Makel MC, Plucker JA. Facts are more important than novelty: Replication in the education sciences. Educ Res 2014;43:304-16.

27. Kazdin AE. Single-case research designs: Methods for clinical and applied settings. Second edition. New York: Oxford University Press; 2011.
28. Stasolla F, Caffò AO, Damiani R, Perilli V, Di Leone A, Albano V. Assistive technology-based programs to promote communication and leisure activities by three children emerged from a minimally conscious state. Cogn Process 2015;16:69-78.

29. Pedhazur E, Schmelkin L. Measurement design and analysis: An integrated approach. New York: Psychology Press; 1991.

30. Kalmar K, Giacino JT. The JFK Coma Recovery Scale-Revised. Neuropsychol Rehabil 2005;15:454-60.

31. Lancioni GE, Sigafoos J, O'Reilly MF, Singh NN. Assistive technology: Interventions for individuals with severe/profound and multiple disabilities. New York: Springer; 2013.

32. Barlow DH, Nock M, Hersen M. Single-case experimental designs: Strategies for studying behavior change. Third edition. New York: Allyn \& Bacon; 2009.

33. Siegel S, Castellan NJ. Nonparametric statistics for the behavioral sciences. Second edition. New York: McGraw-Hill; 1988.

34. Hastie T, Tibshirani R, Friedman J. The elements of statistical learning: Data mining, inference, and prediction. Second edition. New York: Springer; 2009.

35. Munde V, Vlaskamp C. Initiation of activities and alertness in individuals with profound intellectual and multiple disabilities. J Intell Disabil Res 2015;59:284-92.

36. Fischer T, Langner R, Birbaumer N, Brocke B. Arousal and attention: Self-chosen stimulation optimizes cortical excitability and minimizes compensatory effort. J Cognitive Neurosci 2008;20:1443-53.

37. Munde VS, Vlaskamp C, Ruijssenaars AJJM, Nakken H. Alertness in individuals with profound intellectual and multiple disabilities: A literature review. Res Dev Disabil 2009;30:462-80.

38. Eifert B, Maurer-Karattup P, Schorl M. Integration of intensive care treatment and neurorehabilitation in patients with disorders of consciousness: A program description and case report. Arch Phys Med Rehab 2013;94:1924-33.

39. Catania AC. Learning. Fifth edition. New York: Sloan; 2012.

40. Man DWK, Yip PFW, Ko THL, Kwok JKL, Tsang MY. Quality of life of individuals with acquired brain injuries. Appl Res Qual Life 2010;5:27-34.

41. Sunderland N, Catalano T, Kendall E. Missing discourses: Concepts of joy and happiness in disability. Disabil Soc 2009;24:703-14.

42. Scherer MJ, Craddock G, Mackeogh T. The relationship of personal factors and subjective well-being to the use of assistive technology devices. Disabil Rehabil 2011;33:811-7.

43. Gibson BE, Carnevale FA, King G. "This is my way": Reimagining disability, in/dependence and interconnectedness of persons and assistive technologies. Disabil Rehabil 2012;34:1894-9.

44. Näslund R, Gardelli Å. 'I know, I can, I will try': Youths and adults with intellectual disabilities in Sweden using information and communication technology in their everyday life. Disabil Soc 2013;28:2840.

45. Roche L, Sigafoos J, Lancioni GE, O'Reilly MF, Green VA. Microswitch technology for enabling self-determined responding in children with profound and multiple disabilities: A systematic review. Augment Altern Commun 2015;31:246-58.

46. O'Kelly J, James L, Palaniappan R, Taborin J, Fachner J, Magee WL. Neurophysiological and behavioral responses to music therapy in vegetative and minimally conscious states. Front Hum Neurosci 2013;7:884.

47. González-Ortega D, Diaz-Pernas FJ, Martinez-Zarzuela M, AntónRodríguez M. A Kinect-based system for cognitive rehabilitation exercises monitoring. Comput Meth Progr Bio 2014;113:620-31.

48. Lenker JA, Harris F, Taugher M, Smith RO. Consumer perspectives on assistive technology outcomes. Disabil Rehabil: Assist Technol $2013 ; 8: 373-80$.

Conflicts of interest.-The authors certify that there is no conflict of interest with any financial organization regarding the material discussed in the manuscript. Article first published online: September 1, 2016. - Manuscript accepted: August 19, 2016. - Manuscript revised: July 14, 2016. - Manuscript received: April $26,2016$. 